\title{
POLAR STRUCTURE OF SOME BENZEIN INDICATORS
}

\author{
By Myron A. Elliott* and S. F. Acree
}

\section{ABSTRACT}

In the study of electronic effects associated with changes of color of indicators, the approximate electric moments have been measured for $a$-naphtholbenzein and thymolbenzein in benzene solution. The values obtained were $4.3 \times 10^{-18}$ and $6.8 \times 10^{-18} \mathrm{esu}$, respectively. These values are much lower than those predicted for the benzein type of molecule on the basis of the static dipolar structure shown in figure 2. They are compatible, however, with the quinone-phenolate resonance theory and indicate that these molecules are predominantly in the structure shown as $A_{1}$, figure 1 , with very little of the resonant dipolar form $A_{2}$.

\section{CONTENTS}

$\begin{array}{lr}\text { I. Introduction } & \text { Page } \\ & 675\end{array}$

II. Apparatus and method. 677

III. Data and calculations

IV. Sources of error

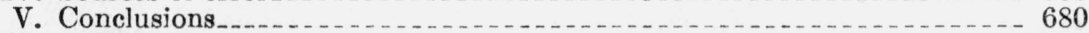

VI. References _... 681

\section{INTRODUCTION}

In investigations of the effects of hydrogen ions and various types of salts on indicators, the need of more information about the dipole moments of the indicators has been felt. Some preliminary data on the dielectric constants of a-naphtholbenzein and thymolbenzein in benzene solutions are given in this paper. From these data the dipole moments of the molecules have been calculated and some interpretations made.

The dipole moment, which is a measure of the electrical asymmetry of a molecule, gives important information concerning molecular structure. Here we shall attempt to correlate the measured dipole moments of some benzein indicators with those predicted by each of two conflicting theories for the structure and origin of color of these indicators. One of these theories [1], ${ }^{1}$ the quinone-phenolate theory, attributes the weak color of the benzeins in their free state to a resonance within the quinone group ( $A$, fig. 1$)$ and the intense color of the ionized molecule to a resonance in the quinone-phenolate anion $(B$, fig. 1). The other theory [2] attributes the color of the free benzein and the highly colored form respectively to a fixed dipolar structure ( $C$, fig. 2) and to a charged, fixed dipolar structure ( $D$, fig. 2).

-Research Associate at the National Bureau of Standards, representing the Florida Citrus Commission.

1 Figures in brackets indicate the literature references at the end of this paper. 
In $A$, the resonance which affects the visible frequencies occurs within the typical quinone group alone, two extreme resonating structures being shown by $A_{1}$ and $A_{2}$, although several intermediate ones can be expected also. In $B$, resonance occurs in the whole quinonephenolate anion; each $\mathrm{C}_{10} \mathrm{H}_{6} \mathrm{O}$ group being thought of as changing alternately between modified quinone and phenolate ion structures [1].

The second theory postulates a trivalent central carbon atom carrying a unit positive charge with a negative charge on the oxygen. This gives the static structures $C$ and $D$, respectively, in place of $A$ and $B$.
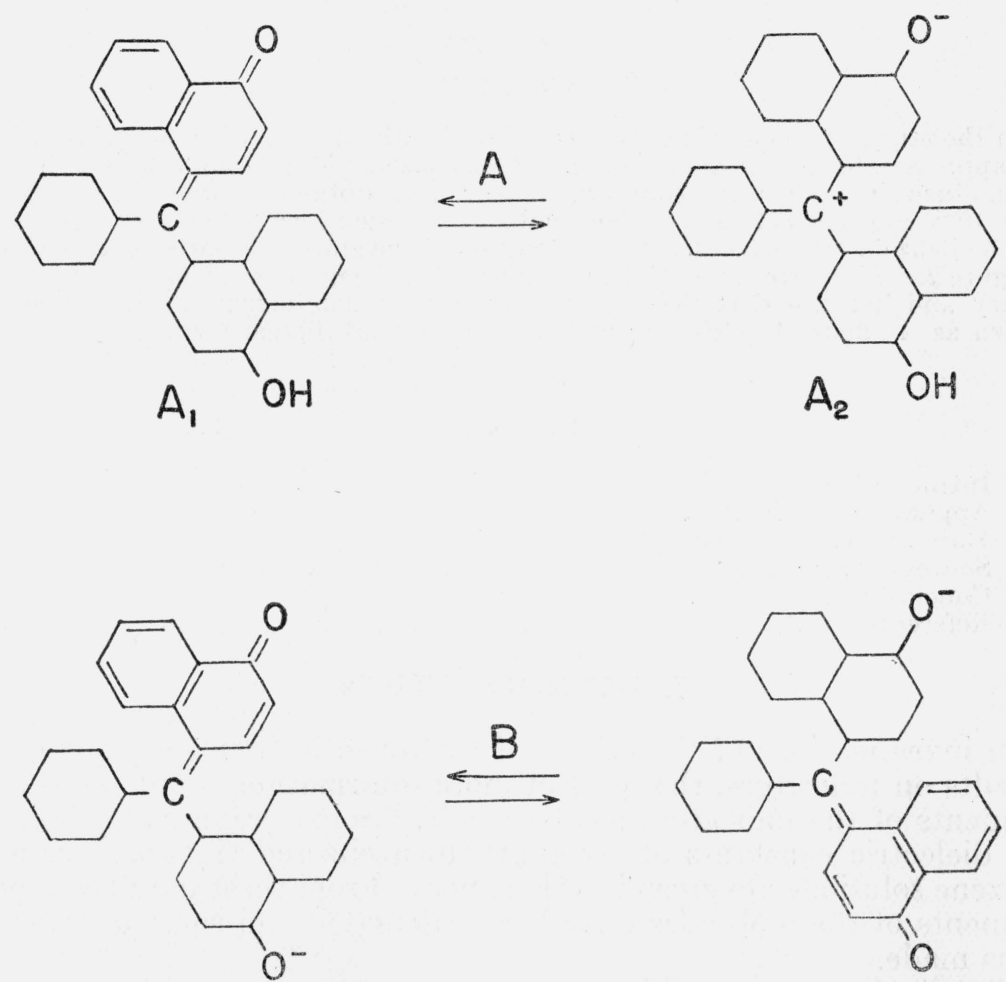

FIgURE 1.-Resonant quinoid and quinone-phenolate structures for a-naphtholbenzein.

$A$, Weakly colored quinoid; $B$, Intensely colored quinone-phenolate anion.

On the basis of the quinone-phenolate theory, $C$ or $D$ is one of the resonance structures of $A$ or $B$, respectively. It should be emphasized, therefore, that one cannot decide against the quinone-phenolate resonance theory by finding chemical reactions in agreement with structures $C$ and $D$. On the other hand, one could obtain evidence against the fixed dipolar structures $(C$ and $D)$ by finding chemical reactions of a quinone. One cannot, however, at present rule out a static dipolar structure on the basis of chemical reactions alone. This can be done by a measurement of the dipole moment, since, as is evident from structures $A$ and $C$, the two theories predict widely different dipole moments for the benzein in its free state or in benzene 
solution. That the benzein has the same form in benzene solution as in its free state, as would be expected from the low dielectric constant of benzene, is shown by the fact that the color is red in both cases, whereas the aqueous alkaline solution containing the ionized molecules is blue.

A simple calculation shows that a molecule having structure $C$ would have a dipole moment close to 27 Debye units $\left(D=10^{-18}\right.$ esu). From structures $A$, on the other hand, one can predict a value somewhere between 3.9 and $27 D$, depending upon the relative probabilities of $A_{1}$ and $A_{2}$. The smaller the value of the measured dipole moment, the less is the contribution of structure $A_{2}$. From the measured dipole moments to be given later, a rough estimation could be made of the

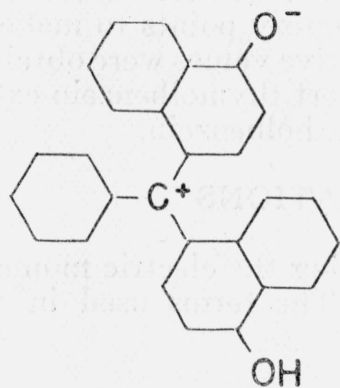

C
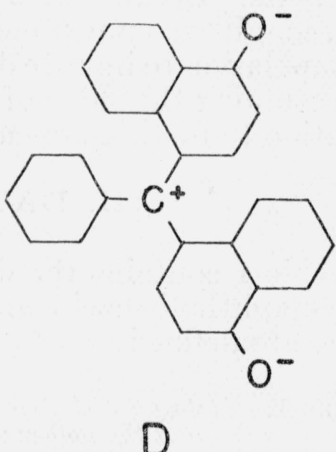

Figure 2.-Postulated static dipolar structures for the weakly and the intensely colored forms of $\alpha$-naphtholbenzein.

relative probabilities of $A_{1}$ and $A_{2}$, if one neglects the intermediate structures which occur to some extent.

\section{APPARATUS AND METHOD}

The above-mentioned moments were calculated from measurements of their dielectric constants, made at $25^{\circ} \mathrm{C}$ with a resonance apparatus of a modified Wyman type placed in an air thermostat [3]. The cell consisted of three concentric platinum cylinders $5 \mathrm{~cm}$ long. The diameter of the central one was $2 \mathrm{~cm}$, and the three cylinders were spaced $1.5 \mathrm{~mm}$ apart. They were mounted in a glass jacket. One heavy straight lead was attached to both the outer and inner cylinders and another to the intermediate cylinder. External inductors of various sizes could be connected across these leads. The resonance frequency of this electric circuit was determined by its interaction with a variable high-frequency oscillator. The interaction was detected by a sudden change in the plate current of the oscillator when its frequency was tuned to the resonance frequency of the nearby cell. The cell was calibrated with standard known solutions of nitrobenzene in benzene and a curve made of frequency against dielectric constant for each of the inductors. The dielectric constants of the solutions were very nearly inversely proportional to the squares of the respective resonance frequencies for a given external inductance. Theoretically, the proportionality should be exact [3] if the solution 
encompassed the total electrostatic field in and about the cell. The frequency of the variable oscillator was checked before and after each measurement by beating it against the higher harmonics of a standard piezoelectric oscillator. This apparatus was built for studying the dielectric constants of solutions of the amino acids and proteins found in citrus juices and is not ideally suited to the type of measurements described here. The values obtained may be considered good enough, however, for use in testing the very different predictions of the two structural theories outlined above. In the range studied, the molar polarization of these benzein indicators in benzene decreased with decreasing concentrations, so it was necessary to extrapolate to infinite dilution to obtain a proper value to use for calculating the electric moments. Because of the low solubility at $25^{\circ} \mathrm{C}$ of thymolbenzein in benzene, it was not possible to obtain satisfactory points to make an extrapolation to infinite dilution. Some tentative values were obtained by assuming the slope of the curve for the short thymolbenzein extrapolation to be the same as that for the $\alpha$-naphtholbenzein.

\section{DATA AND CALCULATIONS}

Table 1 contains the data used in calculating the electric moments of $\alpha$-naphtholbenzein and thymolbenzein. The terms used in this table are defined.

TABLE 1.-Data on dielectric constants and molar polarizations of $\alpha$-naphtholbenzein and thymolbenzein at various concentrations in benzene

\begin{tabular}{|c|c|c|c|c|c|}
\hline$f_{2}$ & e & $P_{1} f_{1}$ & $P_{12}$ & $P_{2}$ & $\begin{array}{c}\text { Fre- } \\
\text { quency }\end{array}$ \\
\hline \multicolumn{6}{|c|}{$\alpha$-NAPHTHOLBENZEIN } \\
\hline $\begin{array}{c}0.00499 \\
.00248 \\
.00123 \\
.000615 \\
.00499 \\
.00248 \\
.00123 \\
.00442 \\
.00218 \\
\text { Values ex }\end{array}$ & $\begin{array}{l}2.442 \\
2.358 \\
2.318 \\
2.299 \\
2.435 \\
2.347 \\
2.312 \\
2.396 \\
2.333 \\
\end{array}$ & $\begin{array}{l}26.646 \\
26.713 \\
26.748 \\
26.764 \\
26.646 \\
26.713 \\
26.748 \\
26.660 \\
26.721 \\
\text { to infinit }\end{array}$ & $\begin{array}{c}29.439 \\
28.057 \\
27.387 \\
27.065 \\
29.346 \\
27.900 \\
27.298 \\
28.700 \\
27.653 \\
\text { dilution }\end{array}$ & $\begin{array}{l}560 \\
543 \\
518 \\
499 \\
542 \\
480 \\
446 \\
460 \\
427 \\
\left\{\begin{array}{l}467 \\
416 \\
348\end{array}\right.\end{array}$ & $\begin{array}{r}M c \\
11.3 \\
11.3 \\
11.3 \\
11.3 \\
13.3 \\
13.3 \\
13.3 \\
39.4 \\
39.4 \\
11.3 \\
13.3 \\
39.4\end{array}$ \\
\hline \multicolumn{6}{|c|}{ THYMOLBENZEIN } \\
\hline $\begin{array}{c}0.000557 \\
.000279 \\
.000557 \\
.000279 \\
.00235 \\
.00133 \\
\text { Values ex }\end{array}$ & $\begin{array}{l}2.321 \\
2.298 \\
2.319 \\
2.300 \\
2.443 \\
2.368 \\
\\
\text { apolate }\end{array}$ & $\begin{array}{l}26.765 \\
26.773 \\
26.765 \\
26.773 \\
26.720 \\
26.740 \\
\\
\text { o infinit }\end{array}$ & $\begin{array}{l}27.373 \\
27.034 \\
27.347 \\
27.056 \\
29.111 \\
28.010 \\
\text { dilution }\end{array}$ & $\begin{array}{r}1092 \\
936 \\
1045 \\
1015 \\
1019 \\
957 \\
\left\{\begin{array}{r}1080 \\
1020 \\
910\end{array}\right.\end{array}$ & $\begin{array}{l}11.3 \\
11.3 \\
13.3 \\
13.3 \\
39.4 \\
39.4 \\
11.3 \\
13.3 \\
39.4\end{array}$ \\
\hline
\end{tabular}


The molar polarization $\left(P_{12}\right)$ of a binary mixture may be expressed $[4$, p. 44$]$ by the equation

$$
\frac{\epsilon-1}{\epsilon+2} \cdot \frac{M_{1} f_{1}+M_{2} f_{2}}{\rho}=P_{1} f_{1}+P_{2} f_{2}=P_{12},
$$

where $\epsilon=$ dielectric constant of the solution;

$\rho=$ density of the solution;

$M_{1}=$ molecular weight of component 1 ;

$M_{2}=$ molecular weight of component 2 ;

$f_{1}=$ mole fraction of component 1 ;

$f_{2}=$ mole fraction of component 2 ;

$P_{1}=$ molar polarization of component 1 ;

$P_{2}=$ molar polarization of component 2 ;

$P_{12}=$ molar polarization of the mixture;

In this case the solvent benzene is taken as component 1 . The constant $P_{1}$ is obtained from eq 1 by letting $f_{1}=1, f_{2}=0$, and substituting the proper constants for benzene,

$$
P_{1}=\frac{\epsilon-1}{\epsilon+2} \cdot \frac{M_{1}}{\rho_{1}}=\frac{2.283-1}{2.283+2} \cdot \frac{78.05}{0.873}=26.778
$$

The total polarization, $P$, of a molecule is the sum of its electronic, atomic, and orientation polarizations. The sum of the electronic and atomic polarizations will be designated as $P_{0}$, the polarization due to deformation of the molecule. The desired orientation polarization will then be $P-P_{0}$. The total polarization, $P$, can be obtained from table 1 and is equal to the value of $P_{2}$ at infinite dilution. The deformation polarization, $P_{0}$, can usually be approximated from measurements of the refractive index, but, because of absorption bands in the visible spectrum, such data could not be obtained here. This $P_{0}$ could also be calculated if another value of the dielectric constant of the solutions were obtained at a frequency in the infrared region that was too great for orientation to occur but low enough for the electronic and atomic deformations to occur. Since it was not feasible in the course of this work to obtain dielectric constant or refractive index data at frequencies in the infrared region, the value of $P_{0}$ was obtained by use of the following approximation:

It may be expected that at frequencies in the infrared the polarization per unit volume for benzene solutions of the benzein indicators will be somewhat greater than that of pure benzene. This is because of the greater possibility for atomic polarization in the large benzein molecules than could occur with pure benzene. For molecules having large moments, however, this" difference between the polarization per unit volume of the solution and that of the pure'solvent at infrared frequencies will be very small compared with the corresponding difference at radio frequencies, where the orientation polarization gives its full effect. This is particularly true if the solute and solvent are composed largely of the same kinds of atoms and groups. Let the approximation be made that the polarization per unit volume of these indicator solutions is equal to that of pure benzene at infrared frequencies. Then it can be calculated that for $\alpha$-naphtholbenzein 
$P_{0}=93 \mathrm{~cm}^{3}$ and for thymolbenzein $P_{0}=116 \mathrm{~cm}^{3}$. The dipole moment $\mu,[4, \mathrm{p} .42]$ of a molecule is given by the formula

$$
\mu=0.0127 \times 10^{-18} \sqrt{\left(P-P_{0}\right) \times T} \text { esu, }
$$

where $T$ is the absolute temperature. The use of eq 3 and values of $P$ obtained from the data of table 1 , of $P_{0}$ as calculated and given above, and of $298.1\left(25^{\circ} \mathrm{C}\right)$ for $T$ gives $4.3 \mathrm{D}$ and $6.8 \mathrm{D}$ for the dipole moments of $\alpha$-naphtholbenzein and thymolbenzein, respectively.

\section{SOURCES OF ERROR}

Careful consideration will show that $P_{0}$ calculated with the above approximation will likely be too small for these particular systems. This means that $\mu$ may, therefore, be a little too large. This fact does not interfere with arguments given here on the polar structure of benzein indicators, since these deductions depend on the moments being below and not above certain limits. Another source of difficulty in working with molecules of this size at high frequencies is that due to the anomalous dispersion of the dielectric constant [4, chap. 5]. This dispersion or variation arises because the molecules may be too large for their orientations to keep pace with the rapid changes in the electric field. If they lag behind these field changes, the dielectric constant, and hence the molar polarization, are diminished relatively to the values at low frequencies. Table 1 shows that the molar polarization of $\alpha$-naphtholbenzein was 348 at 39.4 Mc and 467 at $11.3 \mathrm{Mc}$. To explain this difference one might suspect some colloidal material to be present, but it was found that the solution would readily diffuse through a rubber membrane, so that possibility was discarded. Calculations based on the size of the benzein molecules and the viscosity of the solvent show that the frequency range 7.5 to $27 \mathrm{~m}$ ( 40 to $11 \mathrm{Mc}$ ) is near or perhaps out of the dispersion region on the low frequency side. Wyman in his work on amino acids and related compounds [5] with molecular weights as high as 150 found no evidence of anomalous dispersion at wave lengths down to $2.5 \mathrm{~m}(120 \mathrm{Mc})$. The molecular weights of the benzein derivatives discussed in this paper are between 350 and 400 , but the lowest frequencies used $(27 \mathrm{~m}$ or $11 \mathrm{Mc}$ ) are less than onetenth of those just mentioned. This leads to the belief that at 11 Mc the frequency should be at least near the lower limit of the region of anomalous dispersion if not out of it. Until further work can be done at lower frequencies, the values obtained at $11 \mathrm{Mc}$ are the best available. Any corrections necessary because of anomalous dispersion. will tend to increase the electric moments reported herein. These corrections, if later found to be necessary, will not seriously affect the conclusions concerning the structure of the indicators presented here unless these corrections should exceed 100 percent.

\section{CONCLUSIONS}

The dipole moment of $4.3 \mathrm{D}$ obtained for $\alpha$-naphtholbenzein is only slightly larger than the minimum of $3.9 D$ calculated for structure $A_{1}$. This shows that highly polar states are present only a very small fraction of the time. 
The higher moment of $6.8 \mathrm{D}$ obtained for thymolbenzein indicates that this molecule is in highly polar states somewhat more of the time than $\alpha$-naphtholbenzein.

None of these facts is inconsistent with a structural theory based on the resonance concept, whereas the observed electric moments are not sufficiently large to justify the assumption of the static dipolar structure. Such a dipolar structure can at most exist as only one of many transient states formed during resonance. The theoretical calculations of Pauling [6], Mulliken [7], and Sklar [8] are in accord with a resonance phenomenon for the basis of the origin of color in the conjugated double bond type of molecule. In harmony with this concept, preliminary measurements of the electric moment of phenol blue indicate that resonance between conventional and dipole struc-

$$
\mathrm{O}: \mathrm{C}_{6} \mathrm{H}_{4}: \mathrm{N}-\mathrm{C}_{5} \mathrm{H}_{4} \mathrm{~N}\left(\mathrm{CH}_{3}\right)_{2} \rightleftarrows \overline{\mathrm{O}}-\mathrm{C}_{6} \mathrm{H}_{4}-\mathrm{N}: \mathrm{C}_{6} \mathrm{H}_{4}: \mathrm{N}^{+}\left(\mathrm{CH}_{3}\right)_{2} \text {, }
$$

tures may be associated with the intense color of this indicator, indigoes, oxazones, and similar dyes.

Knowledge of the polar structure of indicators is important in devising equations for expressing the effects of $\mathrm{H}$-ions and salts on their color changes. The equations expressing the corrections for the effects of surrounding salts on a highly polar or amphoteric compound are different from those used in the case of an ordinary ion or molecule [9]. Further measurements of dielectric constants and refractive indices at various temperatures and frequencies and also in ionizing solvents will be necessary. Spectrophotometric data in the infrared should also be obtained to give further information about the bonding in these molecules. Measurements should also be made on similar molecules having the $\mathrm{OH}$ groups replaced by methoxy or acetate radicles so that there can be no hydrogen bond formation [10]. The accumulation and interpretation of such data will aid in perfecting the theory and technique of the indicator method.

We are indebted to J. R. Johnson, of Cornell University, for supplying a number of benzein compounds and to A. L. Sklar, of this laboratory, for many suggestions on the theoretical aspects of this paper.

\section{REFERENCES}

[1] E. A. Slagle and S. F. Acree, Am. Chem. J. 39, 531 (1908); 42, 129 (1909). See also R. T. Birge and S. F. Acree, J. Am. Chem. Soc. 41, 1048 (1919), and Am. Chem. J. $\$ 8,1$ (1907), for earlier references and mathematical treatments of tautomerism of indicators.

[2] H. Lund, Math-fysik. Med. Dansk. 11, 6 (1931).

[3] J. Wyman, Jr., Phys. Rev. 35, 623 (1930).

[4] P. Debye, Polar Molecules (Reinhold Publishing Corp., Inc., New York, N. Y., 1929).

[5] J. Wyman, Jr., Chem. Rev. 19, 213 (1936).

[6] L. Pauling in H. Gilman's Organic Chemistry, 2, 1888-89. (John Wiley \& Sons, Inc., New York, N. Y., 1938).

[7] R. S. Mulliken, J. Chem. Phys. '̈, 20, 121, 364 (1939).

[8] A. L. Sklar, J. Chem. Phys. 5, 669 (1937).

[9] G. Scatchard and J. G. Kirkwood, Physik. Z. 33, 297 (1932).

[10] W. M. Latimer and W. H. Rodebush, J. Am. Chem. Soc. 42, 1419 (1920). W. H. Rodebush and A. M. Buswell, J. Phys. Chem. 219 (1939).

Washington, October 10, 1939. 